https://doi.org/10.48009/1_iis_2010_559-565

\title{
COURSE SEQUENCING AND PERFORMANCE: AN INVESTIGATION OF BUSINESS COLLEGE REQUIREMENTS IN RELATION TO AN INFORMATION SYSTEMS CORE COURSE
}

\author{
Sherry A. Woosley, Ball State University, swoosley@bsu.edu \\ Allen D. Truell, Ball State University, atruell@bsu.edu \\ Melody W. Alexander, Ball State University, malexander@bsu.edu \\ Jensen J. Zhao, Ball State University, jzhao@bsu.edu
}

\begin{abstract}
The purpose of this study was to examine the how course sequencing affects course performance, particularly as these relate to an Information Systems (IS) core course. Specifically, the study examined whether the order of course-taking and the performance in preceding business courses was related to academic performance in the IS core course. Results suggest that course sequencing alone was not related to IS core course performance. But, the study documented significant differences in IS core course performance based on business course performance. Areas of future research are suggested.
\end{abstract}

Keywords: Information Systems Curriculum, Academic Performance, Course Sequencing

\section{INTRODUCTION}

When exploring the issues that affect academic performance in courses, researchers have primarily concentrated on student characteristics and classroom activities, and they have largely overlooked course taking patterns and course sequencing as a predictor of performance. Course sequencing refers to the order that students complete courses. One of the few studies that has specifically examined course sequencing linked course performance with the ordering of macroeconomics and microeconomics [4]. Because the authors used an experimental design, they were able to compare the academic performance of students in two different course taking patterns. They found that one specific sequence (microeconomics followed by macroeconomics) did result in a "higher level of economic understanding" [4, p. 87]. Thus, their results emphasize the importance of course sequencing on learning. But little other research has specifically focused on course order.

Pre-requisites have received some attention in the research. They are one form of required sequencing that is built into the curriculum because students must complete pre-requisites before they can take subsequent courses. Researchers [2, 3, 12] have found that performance in quantitative pre-requisite courses is a statistically significant predictor of economics course performance. Similarly, Rochelle and Dotterweich [10] found performance in an introductory quantitative course was a significant predictor of performance in a business statistics course. Freshman composition and business computer literacy pre-requisites have been shown to predict business communication course performance [9]. Performance in accounting pre-requisites has been linked with intermediate accounting course performance [6] and secondary school accounting has been tied to performance in first year accounting [11]. Researchers [8] have also examined a variety of pre-requisites in relation to MBA course performance and found that a graduate pre-requisite management course was a significant predictor of performance in an MBA organizational behavior course. Yousef [13] investigated predictors of operations research course performance, including performance in other quantitative courses. Thus, the research about prerequisites has included a variety of business disciplines and it has consistently confirmed the relationships between performance in pre-requisites and subsequent course performance.

In addition to pre-requisites, course sequencing may also occur for a variety of other reasons that are not specific to the planned curriculum. Advisors often suggest certain patterns that they believe are more productive. Students may develop patterns because they put courses off. Master schedules may unintentionally create patterns with once-a-year offerings. Regardless of how and why some course sequencing patterns emerge, the patterns themselves may affect course performance particularly if there are relationships in course content. Thus, studies of academic course performance should extend beyond student characteristics to include investigations into the relationships between courses, course taking patterns, and academic course performance.

Overall, the current research about course sequencing and its relationship to academic performance is 
limited primarily to pre-requisites in particular disciplines. Thus, a broader look at course sequencing is warranted.

\section{NEED FOR THE STUDY}

Student academic performance is an important issue to information systems departments, faculty, and chairs. Previous research about academic performance has been done in a variety of business disciplines and has focused on courses in accounting $[6,11,12]$, business statistics [10], economics [2, 3] management [8], and marketing [1, 7]. Yet the research regarding information systems (IS) course performance is more limited.

Therefore, this study fills two gaps in previous research: (1) the need for further information about predictors of academic performance in IS courses, and (2) the need for more information about the patterns in which students take business courses and the relationships of those patterns to academic course performance.

IS programs include a set of general IS core courses that provide a foundation for advanced IS coursework. These core courses, and specifically the first core course, are often taken relatively early in the IS program and they play a critical role in the curriculum. Yet, as a part of an IS program, they may not be required for all business students. In addition, success in these courses may be aided by materials or skills gained in other business courses, even those that are not prerequisites. Thus, a better understanding of an IS core course will be valuable to faculty involved in planning, evaluating, and revising both IS and business curricular requirements. The results of this study may help faculty plan and reinforce curricular decisions such as prerequisites, co-requisites, and optimal course-sequencing.

\section{PURPOSE}

The purpose of this study was to examine course sequencing and course performance, particularly as they relate to an IS core course. Specifically, the study focused on business courses that were business college admissions requirements and examined links between those courses and the IS core course. To explore these courses, the following research questions served to focus the study:

1. Are there significant differences in IS core course performance between students who take specific business courses prior to taking the IS

Volume XI, No. 1, 2010 core course and those who take the business courses after the IS core course?

2. Among the students who take the business courses prior to the IS core course, are there significant differences in IS course performance between (1) the students who perform well in the business courses (i.e., earn an A or A-), (2) those who perform average (i.e., earn a $\mathrm{B}+$ through $\mathrm{C}$ ), and (3) those who do not perform well (i.e., earn a C- or below)?

\section{PROCEDURES}

This section describes the procedures used for this study, including the archival data, the methods for data collection, and the data analyses procedures. Because the study uses existing records (i.e., archival data) and did not involve the identification of individuals, Institutional Review Board approval was not needed.

\section{Archival Data}

Transcript records were used to investigate course sequencing and performance. Data were extracted from the institutional mainframe system. Because the study centered on an IS core course, records related to that course in 2004-05 through 2008-09 were used. These years were chosen because the course content and instruction remained consistent during that timeframe. The IS core course is a 200-level course that focuses on introducing concepts related to developing business information systems. It has one prerequisite, an introduction to business information systems course that is also a requirement for admissions into the business college. The IS core course is the only 200-level course in the IS core required for IS majors. This course is also required for an associate's degree or minor in business information technology. Because the IS core course is a 200-level course, students are able to take it prior to admission into the business college.

In addition to the IS core course, this study used data from transcript records regarding business courses that are required for admission to the business college. These included a first-semester accounting course (Accounting I), a second-semester accounting course (Accounting II), a microeconomics course, a macroeconomics course, a business statistics course, an introductory course in business information systems (which was the pre-requisite to the IS core course), and a business mathematics course. 


\section{Data Collection}

To compile the data files, a three step process was conducted using the institutional mainframe system. First, data regarding the IS core course was extracted from transcript records for all students who took it in sometime between Fall 2004 and Summer 2009. Specifically, four data elements were extracted in the first mainframe step: a student identifier, a year and semester for the IS core course, and a course letter grade. To eliminate performance bias due to course delivery method, courses taken through distance education were excluded from the population.

At the institution which is the site of the study, students are not admitted into the business college until they have reached junior standing and have completed a set of course requirements with a grade point average of at least a 2.25. As stated earlier, this study focused on those requirements. The second step of data collection involved matching the student identifiers found in the first step with data about the other business courses found in transcript records for those same students. The results were a series of data files (one for each business college requirement) which combined the data from the first step (student identifier, year, semester, and IS course grade) with four additional elements from the transcript records (business course number, year taken, semester taken, and course grade).

The final step, which was also conducted on the mainframe system, stripped individual student identifiers from the data files. Thus, the records used for the study were anonymous, individual level data. IS core course grades were translated from a plusminus letter scale to corresponding numbers. For example, As were recoded to 4.000, A-s to 3.667, and $\mathrm{B}+\mathrm{s}$ to 3.333 . This recoding procedure is consistent with how the institution of the study calculates grade point averages. To determine if a student had taken a business course prior to or after the IS course, the year and semester of each business course was compared with the year and semester of the IS core course. That comparison was coded into a categorical variable to indicate course sequencing order (Before or During/After). In addition, business course grades were recoded into three categories: (1) A or A-, (2) $\mathrm{B}+$ through $\mathrm{C}$, or (3) $\mathrm{C}$ - or lower.

\section{Data Analysis}

The dependent variable for the study was performance in the IS core course, as measured by course grade. Because the grades were converted to numeric values, the dependent variable was a continuous variable.

The independent variables for the first research question focused on course sequencing. Therefore, the independent variables were the specific business courses and each included two groups: students who had taken the business course prior to the IS core course and those who had taken the business course simultaneously or after the IS core course.

The independent variables for the second research question focused on performance in the business courses and included three group levels: students who received an A or A-, students who earned between an $\mathrm{B}+$ and $\mathrm{C}$, and students who earned a C- or below.

To explore the differences between groups, one-way analyses of variance were conducted. Appropriate post-hoc multiple comparisons were conducted as follow-up tests to explore the pairwise comparisons. Dunnett's C tests were chosen because they are tailored for data where equal variances cannot be assumed. A p-level of .05 was used to determine statistical significance. Effect size was assessed by $\eta^{2}$ [5].

\section{FINDINGS}

This section describes the findings for the study.

Each research question is addressed and data analysis results are included in tables.

\section{Research Question One}

The first research question asked about differences in the IS core course performance between students who take specific business courses prior to taking the IS course and those who take the business courses after the IS course. As shown in Table 1, the distributions show that students primarily took the business courses before rather than during or after the IS core course, even though this was not required by the curriculum. The findings regarding possible differences in course performance are also included in Table 1 (see below).

With the exception of the first semester accounting course (Accounting I), no significant differences were found in the mean IS core course grades for students who had completed the business requirements prior to the IS course and those who had taken them after the IS course. Although students who took first-semester accounting prior to taking the IS core course had a significantly higher mean GPA in the IS course than the students who did not, the

Issues in Information Systems 
strength of the relationship was small, as assessed by $\eta^{2}$ [5]. Therefore, merely completing business courses prior to the IS core course does not seem to have a big or significant impact on performance in the IS core course.

\section{Research Question Two}

The second research question examined the differences in IS core course performance by performance in business courses. The findings are shown in Table 2.

The mean IS core course GPAs did not significantly differ based on students' performance in the business mathematics course. Yet, the IS course GPAs were related to the GPAs in the other business courses. The strength of the differences was large for accounting, business statistics, microeconomics, and introduction to business information systems, as assessed by $\eta^{2}$ [5]. Dunnett's $C$ tests, which were used to examine the significance of pair-wise differences, confirmed that students who earned As in the business courses also had significantly higher mean GPAs in the IS core course than other students. In other words, earning an $\mathrm{A}$ in the business courses was related to earning higher marks in the IS core course. In addition, students who earned $\mathrm{B}+$ through $\mathrm{C}$ in second semester accounting, macroeconomics, or business statistics had significantly higher mean GPAs in the IS core course than students who earned a C- or below in those courses. (See Table 2 below.)

\section{CONCLUSIONS AND DISCUSSION}

Limitations of this study include a single institution site and a focus on one IS core course. Given the limitations and the results, it is concluded that course sequencing alone does not affect IS core course performance, but performance in preceding business courses does affect IS core course performance.

Regarding course sequencing, most of the ANOVA were not statistically significant (as seen in Table 1). The lack of significant differences suggests a number of possible explanations. First, it may be that the overlap in course content between the business courses and the IS core course is not significant. It is equally possible that enrollment in and completion of a business course is not enough to demonstrate that the student has learned the content of a particular course. For instance, a student who completes a business statistics course with an $\mathrm{F}$ may not have learned the material and thus, that student's subsequent performance in the IS core course would not be improved by the completion of business Volume XI, No. 1, 2010 statistics. This perspective is reinforced by the findings related to course performance.

Among the students who had taken business courses prior to the IS core course, those who performed well in the business courses also had significantly higher mean grade point averages in the IS core course (with the exception of the business mathematics course). The results suggest that students who perform well in business courses may learn content that contributes to their subsequent performance in the IS core course. For instance, students who perform well in a business statistics course may develop analytical thinking skills that are then applicable to the work in the IS core course. This explanation is reinforced by the IS core course performance differences based on introduction to business information systems course performance because the introductory course is a prerequisite for the IS core course. The pre-requisite connection between the courses indicates a similarity in content. These results are also consistent with previous studies that have demonstrated the impact of pre-requisite performance on performance in subsequent courses in other disciplines $[2,3,6,8,9$, $10,12]$. The pre-requisite connection between the introductory IS course and the IS core course may also contribute to the lack of low introduction to business IS course grades in the sample because students who perform badly in the pre-requisite may not continue with additional IS coursework. Thus, students may self-select out of a study such as this. The link between business course performance and IS core course performance may also be due to students themselves. It is possible that high performing students bring a unique set of motivations, skills, and experiences that help them perform well in a variety of courses.

Overall, this study documented that course sequencing alone did not produce significant differences in mean IS core course grades. But, business course performance in preceding courses did produce significant differences in mean IS core course grades. This study contributes to the broader body of research in two ways. First, this study investigated an information systems course - a discipline that has not received attention in the research related to course taking patterns. Second, previous research has focused largely on prerequisites. This study expanded the focus to examine the broader issue of course sequencing and it included courses that are not pre-requisites. Because the study found differences in IS core course performance based on performance in previous business courses, the results support the inclusion of pre-requisites in curricular planning, particularly
Issues in Information Systems 
when the requirement is not just completion of a prerequisite but also a specific level of performance (as defined by course grade) of the preceding courses.

\section{RECOMMENDATIONS FOR FURTHER RESEARCH}

Based on the limitations of and findings from this study, the following recommendations for additional research are offered:

1. Since this study was done at one institution, the study should be replicated on other campuses to investigate whether the lack of differences in course performance due to course sequencing are true in other environments. Specifically, business colleges with different admissions policies and course pre-requisites should be examined.

2. Because this study focused on an IS core course, further research should examine academic performance in other IS courses, such as upperdivision courses and capstone courses.

3. Future research should also explore other student dimensions that may affect the differences found here. Specifically, survey data should be used to investigate motivational and behavioral issues related to academic performance.

\section{REFERENCES}

1. Borde, S. F. (1998). "Predictors of student academic performance in the introductory marketing course," Journal of Education for Business, 73(5), 302-306.

2. Brasfield, D., McCoy, J. \& Milkman, M. (1992). "The effect of university math on student performance in principles of economics," Journal of Research and Development in Education, 25(4), 240-247.

3. Butler, J.S., Finegan, T.A. \& Siegfried, J.J. (1994). "Does more calculus improve student learning in intermediate micro and macro economic theory?" American Economic Review, 84(May), 206-210.

4. Fizel, J. L. \& Johnson, J. D. (1986). "The effect of macro/micro course sequencing on learning and attitudes in principles of economics," Journal of Economic Education, 17(2), 87-98.
5. Green, S.B., Salkind, N. J., \& Akey, T.M. (2000). Using SPSS for Windows: Analyzing and Understanding Data, Upper Saddle River, NJ: Prentice Hall.

6. Huang, J., O'Shaughnessy, J., \& Wagner, R. (2005). "Prerequisite change and its effect on intermediate accounting performance," Journal of Education for Business, 80(5), 283-288.

7. Marcal, L.E., Hennessey, J.E., Curren, M.T. \& Roberts, W.W. (2005). "Do business communication courses improve student performance in introductory marketing?" Journal of Education for Business, 80(5), 289294.

8. Mc-Millan-Capehart, A. \& Adeyemi-Bello, T. (2008). "Pre-requisite coursework as a predictor of performance in a graduate management course," Journal of College Teaching \& Learning, 5(7), 11-16.

9. Plustky, S. \& Wilson, B. (2000). "Study to validate prerequisites in business communication for student success," Journal of Education for Business, 76(1), 15-18.

10. Rochelle, C.F. \& Dotterweich, D. (2007). "Student success in business statistics," Journal of Economics and Finance Education, 6(1), 1924.

11. Rohde, F. H. \& Kavanagh, M. (2009). "Performance in first year university accounting: Quantifying the advantage of second school accounting," Accounting \& Finance, 36(2), 275285.

12. Von Allmen, P. (1996). "The effect of quantitative prerequisites on performance in intermediate microeconomics," Journal of Education for Business, 72(1), 18-22.

13. Yousef, D. A. (2009) . "Success in an introductory operations research course : A case study at the United Arab Emirates University," International Journal of Educational Management, 23(5), 421-430. 
Table 1

ANOVA results for comparisons of mean IS core course GPAs between students who took the course before the IS course and those who took them concurrently or after the IS course.

\begin{tabular}{|c|c|c|c|c|c|c|}
\hline & $\#$ & Mean GPA (sd) & $\mathbf{F}$ & df & $\mathbf{p}$ & $\eta^{2}$ \\
\hline \multicolumn{7}{|l|}{ Accounting I } \\
\hline Took Before & 229 & $3.06(1.16)$ & 4.677 & 1 & .032 & .02 \\
\hline Took During or After & 17 & $2.39(1.85)$ & & & & \\
\hline \multicolumn{7}{|l|}{ Accounting II } \\
\hline Took Before & 196 & $3.04(1.20)$ & .001 & 1 & .970 & .00 \\
\hline Took During or After & 38 & $3.04(1.22)$ & & & & \\
\hline \multicolumn{7}{|l|}{ Business Mathematics } \\
\hline Took Before & 86 & $2.91(1.27)$ & .061 & 1 & .806 & .00 \\
\hline Took During or After & 10 & $2.80(1.58)$ & & & & \\
\hline \multicolumn{7}{|l|}{ Business Statistics } \\
\hline Took Before & 195 & $3.09(1.09)$ & 1.119 & 1 & .291 & .01 \\
\hline Took During or After & 52 & $2.90(1.38)$ & & & & \\
\hline \multicolumn{7}{|l|}{ Macroeconomics } \\
\hline Took Before & 214 & $3.06(1.18)$ & 2.906 & 1 & .090 & .01 \\
\hline Took During or After & 29 & $2.64(1.58)$ & & & & \\
\hline \multicolumn{7}{|l|}{ Microeconomics } \\
\hline Took Before & 292 & $3.02(1.20)$ & 1.271 & 1 & .260 & .00 \\
\hline Took During or After & 12 & $2.61(1.71)$ & & & & \\
\hline
\end{tabular}

Note: The introduction to business systems course was not included in this analysis because it is a pre-requisite for the IS core course and thus students do not have the option of taking it concurrently or after the IS core course. 
Table 2

ANOVA and Follow-up Dunnett's C tests for comparisons of mean IS core course GPAs between students who performed at different levels in the business courses.

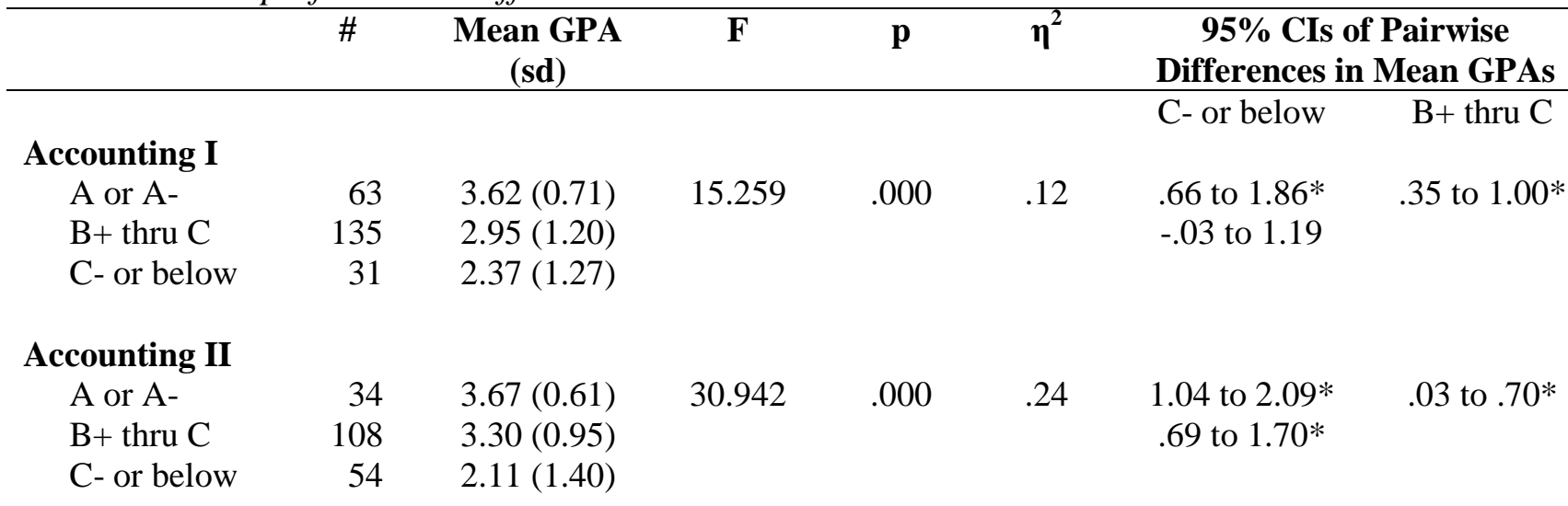

\section{Business}

Mathematics

$\begin{array}{lrlrrr}\text { A or A- } & 9 & 2.96(1.37) & 1.052 & .354 & .02 \\ \text { B+ thru C } & 50 & 3.05(1.26) & & & \\ \text { C- } \text { or below } & 27 & 2.62(1.24) & & \end{array}$

\section{Business}

Statistics

$\begin{array}{lrllllll}\text { A or A- } & 31 & 3.85(0.31) & 17.192 & .000 & .15 & .90 \text { to } 1.67 * & .40 \text { to } .96^{*} \\ \text { B+ thru C } & 104 & 3.17(1.05) & & & & .17 \text { to } 1.04 * & \\ \text { C- or below } & 60 & 2.56(1.17) & & & & \end{array}$

\section{Intro. Business}

\section{Information}

Systems

$\begin{array}{lrllllll}\text { A or A- } & 22 & 3.68(0.88) & 6.409 & .003 & .15 & \text { NA } & .39 \text { to } 1.66^{*} \\ \text { B+ thru C } & 52 & 2.66(1.28) & & & & \text { NA } & \\ \text { C- or below } & 2 & 1.83(2.59) & & & & \end{array}$

\section{Macroeconomics}

$\begin{array}{lrrrrrrr}\text { A or A- } & 20 & 3.73(0.47) & 13.822 & .000 & .12 & .76 \text { to } 1.81^{*} & .18 \text { to } .85^{*} \\ \text { B+ thru C } & 136 & 3.22(1.02) & & & & .27 \text { to } 1.27^{*} & \\ \text { C- or below } & 58 & 2.45(1.44) & & & & & \\ & & & & & & & \\ \text { Microeconomics } & & & & & & & \\ \text { A or A- } & 38 & 3.60(0.92) & 7.557 & .001 & .05 & .40 \text { to } 1.43^{*} & .15 \text { to } .99^{*} \\ \text { B+ thru C } & 182 & 3.03(1.18) & & & & -.07 \text { to } .77 & \\ \text { C- or below } & 72 & 2.68(1.29) & & & & \end{array}$

Note: An asterisk indicates that the $95 \%$ confidence interval does not contain zero, and therefore the difference in means is significant at the .05 significance using Dunnett's C procedure.

NA - Because the group of students who received C-or below included only 2 people, pairwise comparisons for this group were not appropriate. 